\title{
Osmotic stress induces severe decrease in cation exchange capacity and surface groups of medium acidity in roots of cereal plants
}

\author{
Malgorzata Lukowska $^{1}$ - Grzegorz Józefaciuk ${ }^{1}$
}

Received: 2 March 2015/Revised: 10 December 2015/ Accepted: 11 December 2015/Published online: 2 January 2016

(C) The Author(s) 2015. This article is published with open access at Springerlink.com

\begin{abstract}
Huge amount of information on the plants response to drought is available throughout the literature; however, extremely rare information concerns effects of limited water availability on cation exchange capacity (CEC) and surface acidity of plant roots despite their importance for cations uptake by plants. As it is known, the CEC and acidity of barley roots markedly decrease under a low soil moisture and osmotic stresses, so we studied the behavior of the other cereal plants. Surface charge properties of roots of wheat, triticale, rye, oats and barley grown in hydroponics under osmotic stress induced at tillering stage by various mannitol concentrations were determined using a back-titration method. Roots size distributions were measured also. The osmotic stress caused down to a fivefold decrease in the CEC and a twofold decrease in the relative amount of surface functional groups of medium acidic strength, whereas no well-defined trends were observed for surface acidity. The above changes were the highest for rye and the lowest for oats. The general root's architecture remained roughly same; however,' the roots length markedly decreased under stress. The smallest decrease in roots length was observed for barley. Decrease in CEC and roots length may be the primary reasons for severe limitation in nutrient uptake by plants during drought.
\end{abstract}

Communicated by R. Aroca.

Grzegorz Józefaciuk

jozefaci@ipan.lublin.pl

1 Institute of Agrophysics, Polish Academy of Sciences, Doswiadczalna 4 Str., 20-290 Lublin, Poland
Keywords Architecture - CEC - Drought - Osmotic . Roots $\cdot$ Stress $\cdot$ Titration

\section{Introduction}

The response and adaptive mechanisms of plants to drought are under an increasing interest of many researchers (De Micco and Aronne 2012; Zlatev and Lidon 2012), that to high extent is connected with threats of a recent climate changes (Nezhadahmadi et al. 2013). Soil moisture deficit environments affect at first the plant roots. Not only the roots biomass, length, density and depth undergo marked changes, but more subtle variations in protein composition, enzyme activities, gene expression patterns (Bian and Jiang 2009; Oh and Komatsu 2015; Shan et al. 2015; Subbarao et al. 1995) occur, as well. The cation exchange capacity (CEC) of the roots, governing the ions ratio and their uptake by plants, changes under different stressing conditions that was reported for aluminum and heavy metals toxicity (Jozefaciuk and Szatanik-Kloc 2004; Szatanik-Kloc 2010). Lukowska and Jozefaciuk (2013) found that low soil moisture and osmotic stresses decreased the CEC and variable charge of barley roots and increased their average values of surface dissociation constants. Therefore we hypothesized that drought stress affects roots surface charge properties of other cereal plants, as well, that up to date remains a question. Since roots taken from a soil may loose their finest parts adhered to the soil material and some of the soil colloids adhered to the roots may be sampled, instead of the low soil moisture, we performed hydroponic experiments with mannitol-induced osmotic stress.

To estimate plants root CEC and characterize an acidic strength of the surface charge generating groups we used a 
back-titration method (Meychik and Yermakov 2001; Nederlof et al. 1993). Since drought stress affects roots growth and development (Blum 1996), we also studied the roots length distributions to provide the biometric background of the plants reaction on the applied stressing conditions.

\section{Materials and methods}

Roots of barley Hordeum vulgare (Quench), oats Avena sativa (Siwek), triticale Triticosecale (Nagano), wheat Triticum aestivum L. (Tybalt), rye Secale cereale (Visello) were studied. The plant growth was performed in exactly the same way as in our previous studies described by Lukowska and Jozefaciuk (2013), as briefly summarized below. Thirty 3-day germinated seeds of the studied plants were grown in the Hoagland nutrient solution at $16 \mathrm{~h} /$ $8 \mathrm{~h}$ day/night regime at $20 \pm 5{ }^{\circ} \mathrm{C}$. After 14 days the tillering stage plants were transferred to new nutrient solutions containing different concentrations of a mannitol: 0 (control), $0.025 \mathrm{~mol} \mathrm{dm}^{-3}$ (corresponding to a soil water potential $\quad \psi=-0.6 \mathrm{MPa}) ; \quad 0.05 \mathrm{~mol} \mathrm{dm}^{-3}$ $(\psi=-1.3 \mathrm{MPa})$ and $0.075 \mathrm{~mol} \mathrm{\textrm {dm } ^ { - 3 }}(\psi=-1.8 \mathrm{MPa})$ and all plants were grown for the next 7 days. Then all plant roots were harvested and washed with a distilled water. The experiment was replicated thrice. Each of the replicated material was studied separately and the data presented result from their averages.

The whole roots (two plants from each replicate) were spread upon a glass tray filled with $\sim 2$-mm-deep distilled water and scanned by a flatbed scanner Epson XL 10000 (Seiko Epson Corporation) with a transparency unit adapter. Scanning was performed at 400 dpi resolution in a positive mode and 8-bit grey-scale, with all image enhancements turned off, in six replicates. All images were taken with the same settings of the scanning system. From the obtained images lengths and diameters of each root were evaluated using WinRhizo PRO software provided by Regent Instruments Inc., Canada (Nosalewicz and Lipiec 2014).

All harvested roots were then washed in diluted $\mathrm{HCl}$ and in distilled water, air dried, cut onto around 5-mm long pieces, suspended in $1 \mathrm{~mol} \mathrm{dm}^{-3} \mathrm{NaCl}$, adjusted to pH 2.95 and slowly titrated upwards under the atmosphere of nitrogen. In paralle, the titration curve of the supernatant $\left(1 \mathrm{~mol} \mathrm{dm}{ }^{-3} \mathrm{NaCl}\right.$ solution) was determined. Three titration curves were measured for roots coming from each experimental replicate and the differences between nine curves (three curves for each of the three stress replicates) of the roots grown at that same water potential were up to $10 \%$. This is worth mentioning that during the continuous titration the equilibrium conditions are not reached; therefore the titration curves do not give absolute values, and they shall be rather used for comparative purposes.

The titration curves were interpreted in terms of surface charge and acidity of surface functional groups. This was assumed that the base used for the titration of the whole suspension, $N_{\text {susp }}$, is consumed for neutralization of acids present on the roots surface, $N_{\mathrm{s}}$, and by acids present in the solution, $N_{\text {sol }}$ :

$N_{\text {susp }}=N_{\mathrm{s}}+N_{\text {sol }}$

Because neutralization of acidic groups, $\mathrm{AH}$, present on the root tissue surface, $S$, in the reaction: $\mathrm{SAH}+\mathrm{OH}^{-}=\mathrm{SA}^{-}+\mathrm{H}_{2} \mathrm{O}$ produces negatively charged surface anions, $\mathrm{SA}^{-}$, that leads to an increase in a variable surface charge, $Q_{\mathrm{v}}$, of the roots,), the $N_{\mathrm{s}}$ versus $\mathrm{pH}$ dependence may be treated as $Q_{\mathrm{v}}$ versus $\mathrm{pH}$ dependence: (apparent) surface dissociation constant, $\mathrm{p} K_{\text {app }}$, dependence (Nederlof et al. 1993):

$N_{\mathrm{s}}(\mathrm{pH})=Q_{\mathrm{v}}(\mathrm{pH})$

Assuming that at the beginning of the titration, at low $\mathrm{pH}$, the $Q_{\mathrm{v}}$ equals zero, the amount of $N_{\mathrm{s}}$ consumed within the whole experimental window, $N_{\text {tot }}$, may be regarded as the total surface charge of the roots, $Q_{\mathrm{v}_{\text {tot }}}$, whereas the amount of base consumed during the titration to $\mathrm{pH}=7$ was taken as the roots CEC (Williams and Coleman 1950; Heintze 1964.

The titration of plant roots involves neutralization of many surface groups of different acidic strength, defined by apparent dissociation constants:

$K_{\text {app }}=\frac{\left(\mathrm{SA}^{-}\right)\left(\mathrm{H}^{+}\right)}{(\mathrm{SAH})}$

If half of a surface acid is neutralized $\left(\left(\mathrm{SA}^{-}\right)=((\mathrm{SAH}))\right.$ one can see that $K_{\text {app }}=\left(\mathrm{H}^{+}\right)$and $\mathrm{p} K_{\text {app }}=\mathrm{pH}$ and the titration curve may be translated to $N_{\mathrm{s}}$ versus $\mathrm{p} K_{\text {app }}$ dependence:

$N_{\mathrm{s}}(\mathrm{pH})=N_{\mathrm{v}}\left(\mathrm{p} K_{\text {app }}\right)$

A normalized distribution function of apparent surface dissociation constants, $f\left(\mathrm{p} K_{\text {app }}\right)$, may be determined as the first derivative of $N_{\mathrm{s}}\left(\mathrm{p} K_{\text {app }}\right)$ on $\mathrm{p} K_{\text {app }}$ divided by $N_{\text {tot }}$ :

$f\left(\mathrm{p} K_{\text {app }}\right)=1 / N_{\text {tot }} \mathrm{d} N_{\mathrm{v}}\left(\mathrm{p} K_{\text {app }}\right) / \mathrm{dp} K_{\text {app }}$

The average value of $\mathrm{p} K_{\mathrm{app}}, \mathrm{p} K_{\mathrm{app}, \mathrm{av}}$, was then calculated as:

$\mathrm{p} K_{\mathrm{app}, \mathrm{av}}=\int \mathrm{p} K_{\mathrm{app}} f\left(\mathrm{p} K_{\mathrm{app}}\right)$.

All details of the titration procedure as well as on theoretical interpretation of experimental data can be found in (Jozefaciuk et al. 2014). 


\section{Results}

Changes in root architecture after osmotic stress is shown in Fig. 1. The presented barley root scans illustrate a general rule for all plants studied that development of finer roots is consecutively suppressed at increasing stress intensity. This tendency is explicitly presented in Fig. 2 showing distribution functions of finer $(<1 \mathrm{~cm})$ root lengths after stress for barley and triticale as the examples. For all studied plants stress induced a decrease of fine roots length practically in each range of their dimensions; therefore the overall shape of the distribution functions was only slightly affected by stress (the lowest variations occured for barley and the highest for triticale, and this was a reason for selection of these plants for the illustration). For all plants studied the total length of the roots decreased with increasing stress levels as illustrated in Fig. 3. Stress has the smallest effect on the total length of barley roots. After -0.6 MPa stress they decrease to $91 \%$ length of the control roots, after $-1.3 \mathrm{MPa}$ stress to $65 \%$ and after $-1.8 \mathrm{MPa}$ stress to $46 \%$. The relative decrease of total length of roots of rye, oat, wheat and triticale is roughly similar: on average the root lengths of these plants decrease to 61,44 and $32 \%$, at respective stress levels. This is worth
Fig. 1 Representative scans of barley roots developed at various water potentials $\psi$ in osmotic stress conditions induced by mannitol

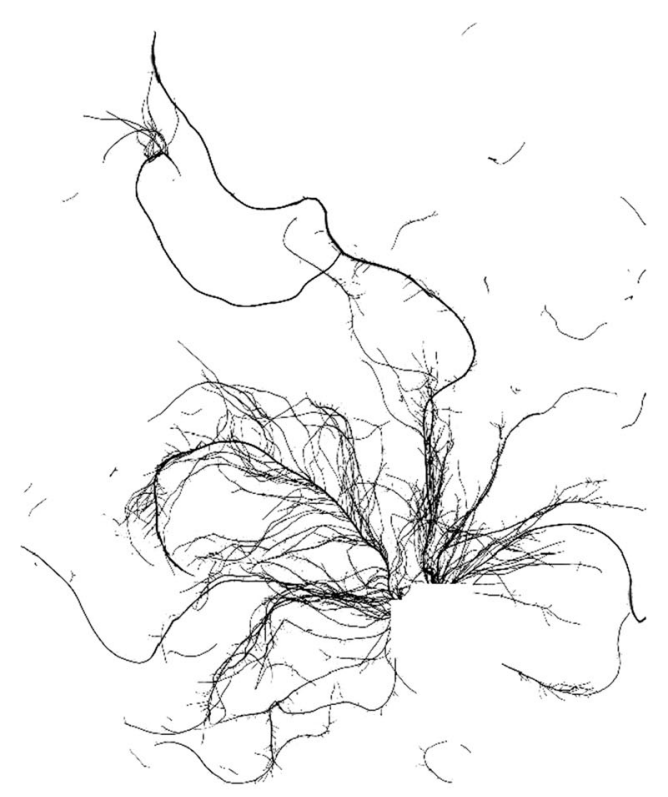

control

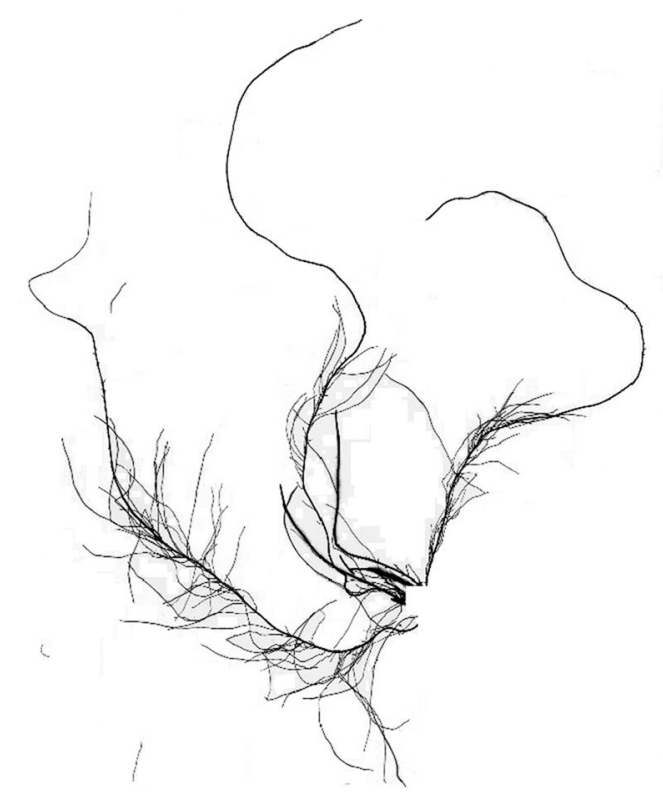

$\Psi=-1.3$

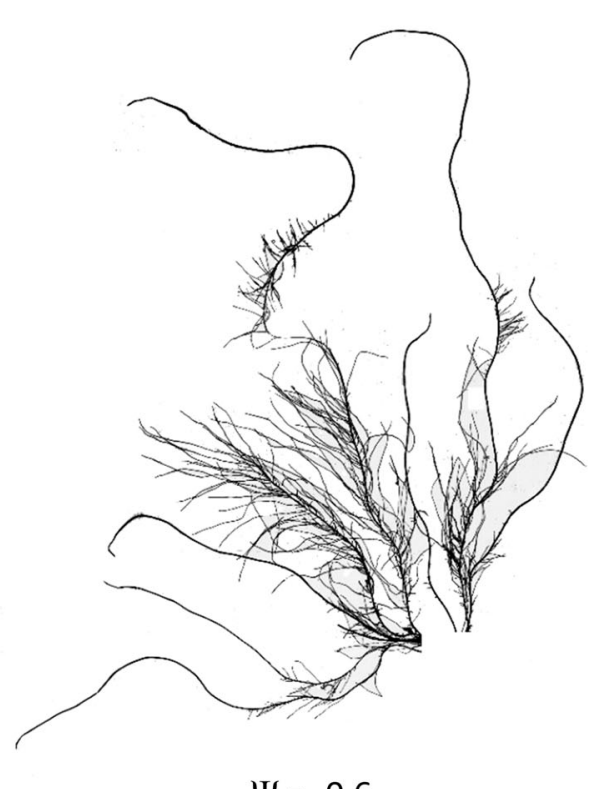

$\Psi=-0.6$

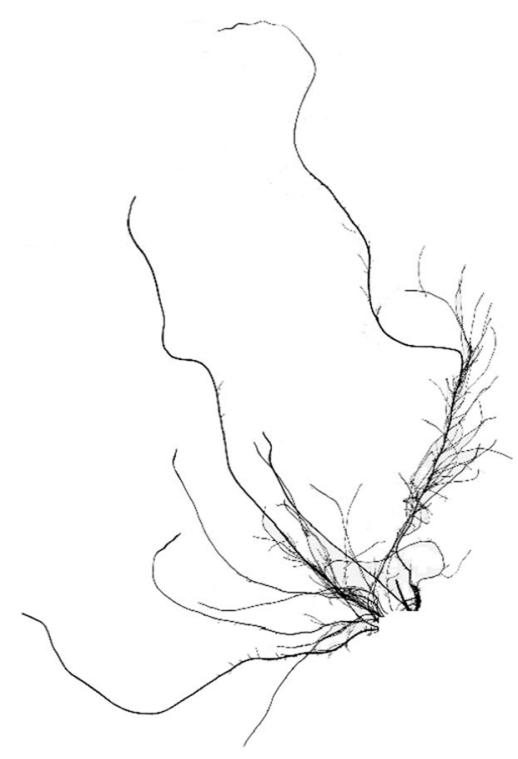

$\Psi=-1.8$ 
Fig. 2 Roots lengths distribution functions for barley and triticale grown at various water potentials $\psi$ in osmotic stress conditions induced by mannitol. Error bars $\pm \mathrm{SD}$

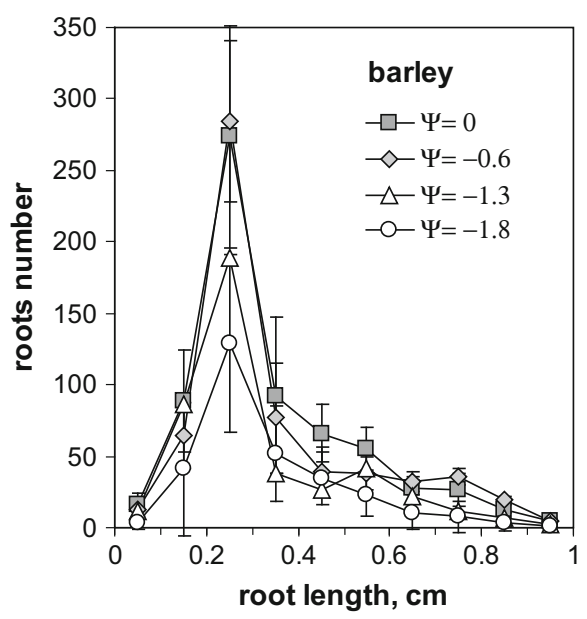

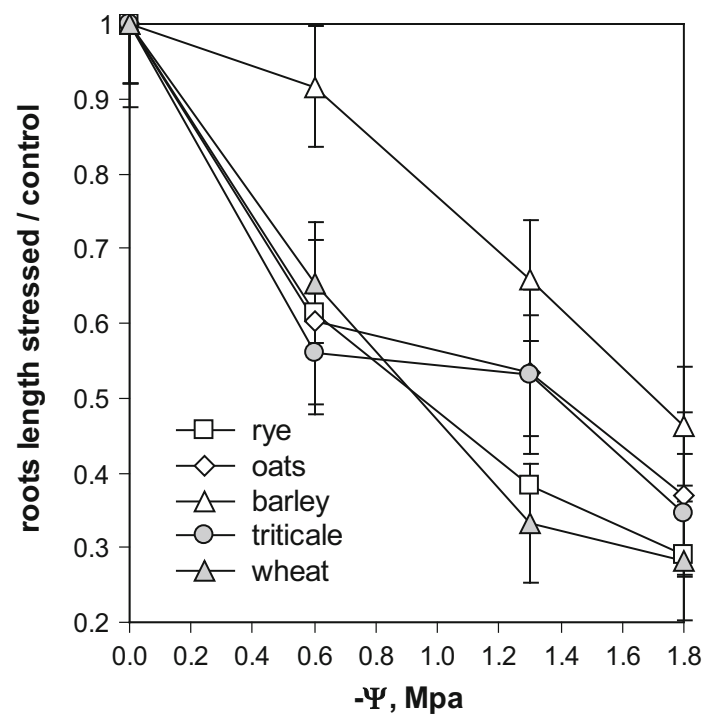

Fig. 3 Total lengths of the roots of the studied plants grown at various water potentials $\psi$ in osmotic stress conditions induced by mannitol. Error bars $\pm \mathrm{SD}$

to mention that an average diameter of the control roots of rye, oats, barley and wheat is similar and ranges between 0.36 to $0.39 \mathrm{~mm}$, whereas the roots of triticale are thicker $(0.53 \mathrm{~mm})$. Average root diameter of the stressed roots remains practically unchanged for most plants and stress conditions, and only at the highest $-1.8 \mathrm{MPa}$ stress the roots of wheat thickened to $0.50 \mathrm{~mm}$ and roots of oats became thinner $(0.25 \mathrm{~mm})$.

The titration curves (suspension minus supernatant) of the studied control roots along with their apparent surface dissociation constants distribution functions are presented in Fig. 4. Despite significant differences in the amount of base consumed by particular roots, all titration curves are similar in shape and exhibit two inflection points. For all studied roots the $\mathrm{p} K_{\mathrm{app}}$ distribution functions are
W-shaped. Weakly acidic charge-generating groups $\left(\mathrm{p} K_{\text {app }}>9\right)$ dominate in all plants but triticale, for which strongly acidic groups $\left(\mathrm{p} K_{\text {app }}<4\right)$ prevail. Well developed peak of medium acidic groups $\left(5.5<\mathrm{p} K_{\text {app }}<6.5\right)$ is present in all roots. Values of total variable charge, CEC and average values of apparent surface dissociation constants for the nonstressed (control) roots are shown in Table 1. The lowest total variable charge have roots of rye and the highest - these of barley. Barley and triticale roots have the highest CEC's and the lowest CEC have roots of rye. Average apparent surface dissociation constants of the control roots are similar for all plants but triticale, for which the $\mathrm{p} K_{\text {app,av }}$ is the lowest (the surface acids are relatively stronger).

Changes in roots titration curves and in apparent surface dissociation constants distribution functions under the osmotic stress is exemplary illustrated in Fig. 5 for rye and wheat, respectively. The observed disappearance of inflection points on the titration curves together with marked decrease in the peak of medium acidic groups on the distribution functions is a rule for the other plants studied, as well.

Figure 6 presents the relative changes in the cation exchange capacity and in the average values of the apparent surface dissociation constants of the studied roots under the osmotic stress of increasing intensity. In this figure, the ratio of a given parameter of the stressed roots to its value for the control root is presented on the $y$-axis. The continuous decrease in CEC with increasing stress intensity is observed for all plants roots. Very similar dependence is seen for the total variable charge of the roots, that is not presented because $Q_{\mathrm{v}_{\text {tot }}}$ and CEC are roughly proportional. Negligible changes in $\mathrm{p} K_{\text {app }}$ are observed (Fig. 6) despite distribution functions of apparent surface dissociation constants (see Fig. 5) show marked differences between fractions of surface groups of different acidic strength ( $\mathrm{p} K_{\text {app }}$ values) in stressed and nonstressed roots. To better 
Fig. 4 Titration curves (left) and apparent surface dissociation constants distribution functions (right) of the nonstressed control roots $(\psi=0)$. Average curves for roots of each plant are plotted. The titration curves points are large enough to mask $\pm \mathrm{SD}$ error bars. For $\mathrm{p} K_{\text {app }}$ distributions the error bars are given only for triticale not to shadow the details
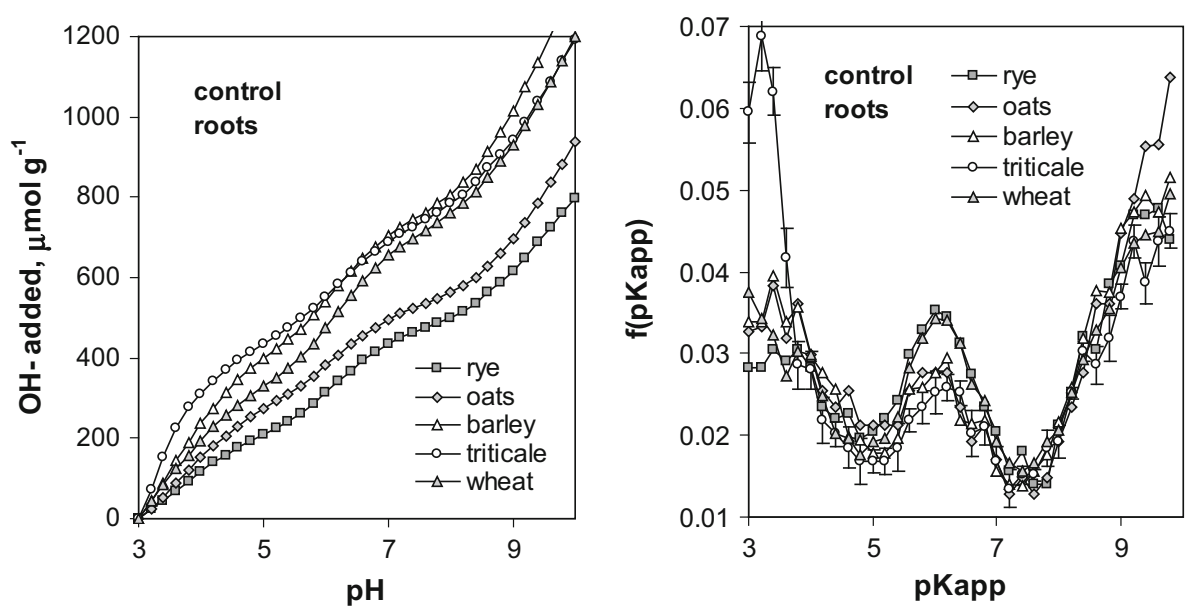

Table 1 Total variable charge, CEC and average values of apparent surface dissociation constants, $\mathrm{p} K_{\text {app,av }}$, of the control roots \pm SD values

\begin{tabular}{lllccc}
\hline & Rye & Oats & Triticale & Wheat & Barley \\
\hline$Q_{\text {tot }}\left(\mu \mathrm{mol} \mathrm{g}^{-1}\right)$ & $797 \pm 25$ & $940 \pm 29$ & $1190 \pm 34$ & $1200 \pm 56$ & $1330 \pm 42$ \\
$\mathrm{CEC}\left(\mu \mathrm{mol} \mathrm{g}^{-1}\right)$ & $434 \pm 14$ & $494 \pm 17$ & $690 \pm 19$ & $655 \pm 28$ & $705 \pm 22$ \\
$\mathrm{p} K_{\text {app,av }}$ & $6.76 \pm 0.07$ & $6.79 \pm 0.07$ & $6.36 \pm 0.05$ & $6.71 \pm 0.05$ & $6.73 \pm 0.06$ \\
\hline
\end{tabular}
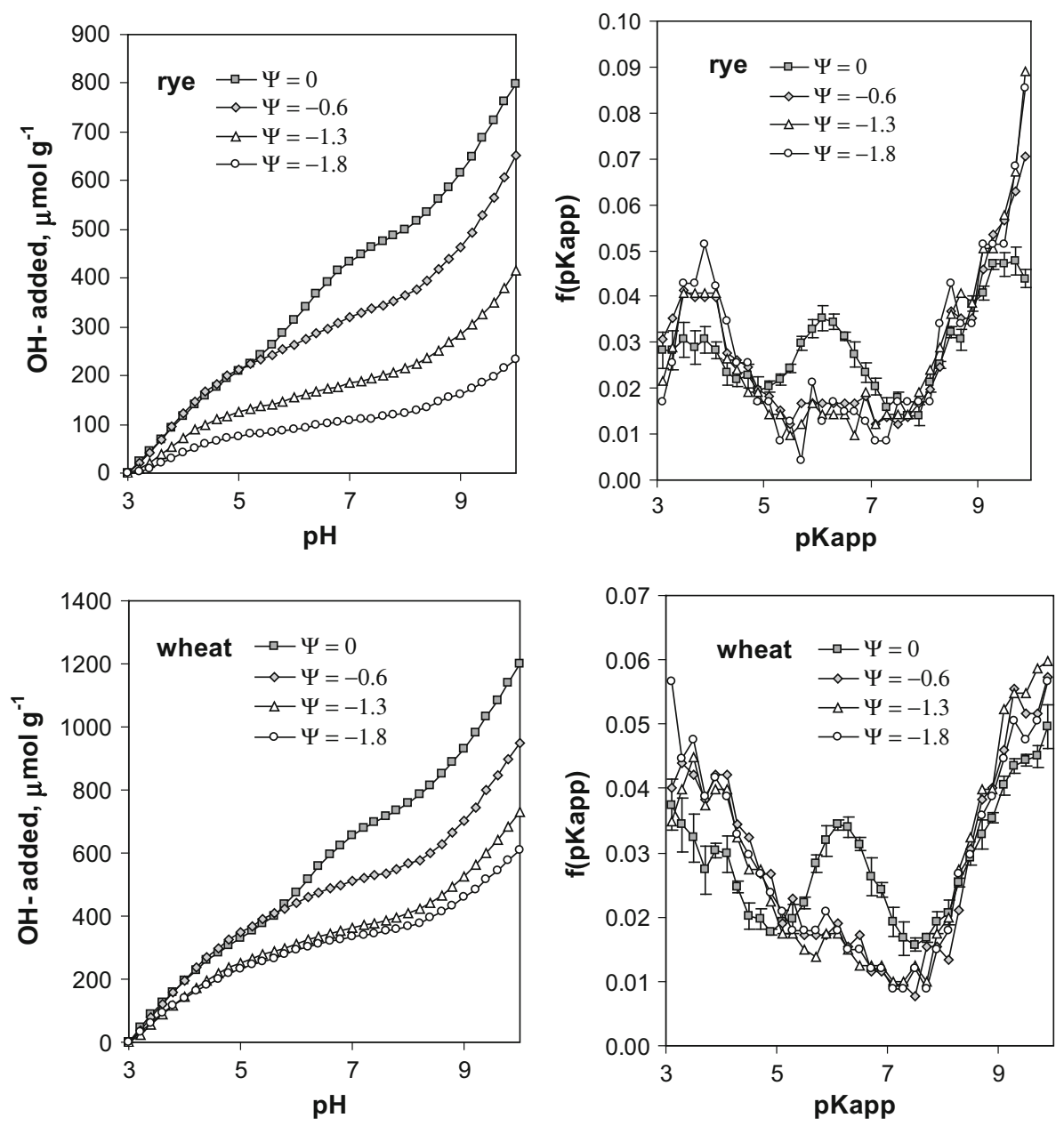
Fig. 6 Relative changes in CEC (left) and in average value of $\mathrm{p} K_{\text {app }}(r i g h t)$ of the studied roots grown at various water potentials $\psi$ in osmotic stress conditions induced by mannitol. On $y$-axis the ratio of the CEC (or $\mathrm{p} K_{\text {app,av }}$ ) of the roots grown at osmotic stress to the CEC (or $\left.\mathrm{p} K_{\text {app,av }}\right)$ of the control roots is given. The control roots (points at $C=0$ ) were grown without mannitol addition at $\psi=0$. Average values for each treatment are depicted. Error bars $\pm \mathrm{SD}$
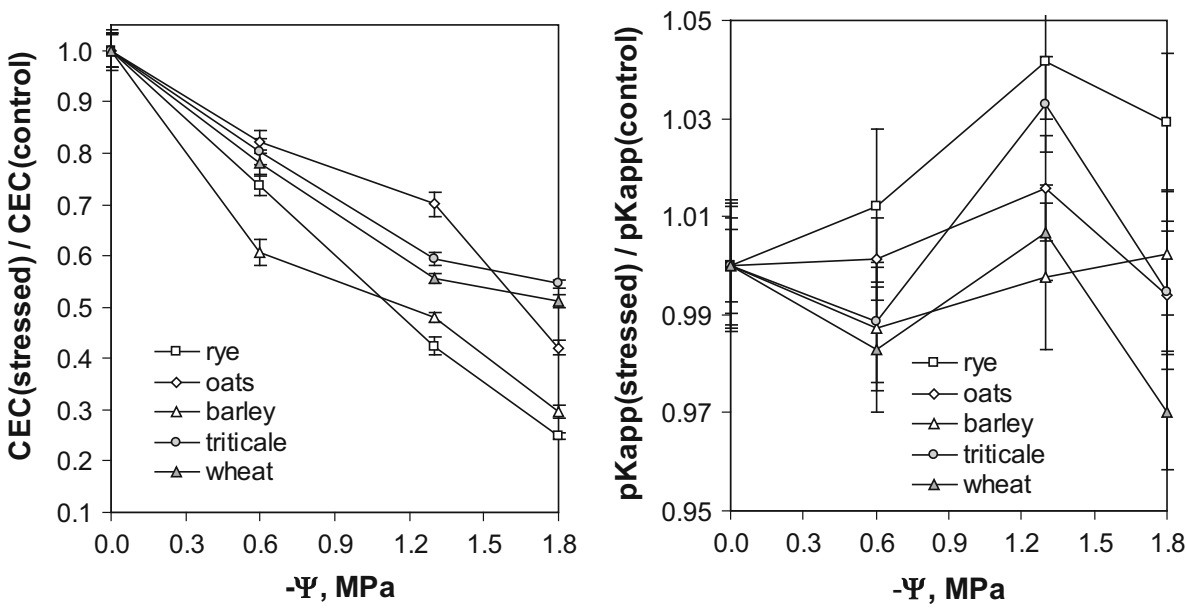

Table 2 Fractions $(f)$ of surface functional groups of medium (MA) and weak (WA) acidities of the control roots \pm SD values

\begin{tabular}{llllll}
\hline & Rye & Oats & Triticale & Wheat & Barley \\
\hline$f_{\text {MA }}$ & $0.335 \pm 0.02$ & $0.281 \pm 0.02$ & $0.259 \pm 0.02$ & $0.324 \pm 0.03$ & $0.273 \pm 0.02$ \\
$f_{\text {WA }}$ & $0.402 \pm 0.02$ & $0.430 \pm 0.01$ & $0.375 \pm 0.01$ & $0.402 \pm 0.02$ & $0.428 \pm 0.01$ \\
\hline
\end{tabular}

observe these changes we divided all surface functional groups onto three parts: strongly acidic (SA, $\mathrm{p} K_{\text {app }}$ between 3 and 5), medium acidic (MA, p $K_{\text {app }}$ between 5 and 7) and weakly acidic (WA, $\mathrm{p} K_{\text {app }}$ higher than 7). The fractions of medium and weakly acidic groups for the studied control roots are presented in Table 2. The fraction of strongly acidic groups equals 1 minus sum of the previous two values. The most acidic surface have the roots of triticale, for which the fraction of acidic groups, $f_{\mathrm{SA}}$, equals 0.366 . The next go barley $\left(f_{\mathrm{SA}}=0.299\right)$, oats $\left(f_{\mathrm{SA}}=0.289\right)$ and wheat $\left(f_{\mathrm{SA}}=0.274\right)$. The acidic character of the root surface is the lowest for rye $\left(f_{\mathrm{SA}}=0.263\right)$.

Figure 7 presents the relative changes in the medium and weakly acidic surface groups of the studied roots under osmotic stress of increasing intensity. Generally the increase in stress level induces a decrease in root surface groups of medium acidity and increase in the fraction of weakly acidic groups for all plants. Some decrease in the fraction of the latter groups is noted at the highest ( $\psi=-1.8)$ stress, however the $f_{\mathrm{WA}}$ is still higher then for the control roots. Also the fraction of strongly acidic groups is in all cases higher for the stressed than for the nonstressed roots; however, the trends in its changes with the stress level (data not presented) are not so well pronounced as for MA and WA groups.

\section{Discussion}

Plant response to the osmotic and low soil moisture stresses has been frequently assayed basing on root length changes, and this is generally accepted that in dry soils roots grow deeper and very fine root branches are developed (Moayedi et al. 2009). Genotypes developing longer roots under low moisture conditions are able to access deeper soil water and the increase in root length is regarded as an adaptive response of plants on stress (Radhouane 2007). Contrary to the above findings, our observations show that the root length of all plants studied decreases simultaneously in all ranges of its dimensions thus preserving very similar shapes of root distributions in both stressed and nonstressed conditions (see Fig. 2). Thus the roots neither elongate nor develop fine branches under the applied stress. However, significant influence of the osmotic stress on roots surface charge properties was observed. Decrease in roots CEC may cause severe limitation of cationic nutrients uptake under drought conditions. Since the root surface charge is positively correlated with root specific surface (SzatanikKloc 2010), a decrease in surface area at drought can occur, as well. This can diminish the intensity of water lost by roots; however, the water uptake can be reduced. Changes in root-specific surface area under low miosture stress will be a subject of our further studies.

Roughly that same values of apparent surface dissociation constants for all plants studied (see Table 2) and similar shapes of $\mathrm{p} K_{\text {app }}$ distribution functions (see Fig. 5) indicate that overall composition and chemical character of surface acidic groups on intact (nonstressed) tissues of cereal roots are rather similar. Despite the overall root surface acidity is not affected by osmotic stress (see $\mathrm{p} K_{\text {app }}$ in Fig. 6), changes in amounts of surface groups of various acidic strengths occur. Particularly evident is a sharp decrease of medium acidic groups accompanied by a slight increase in the fraction of strongly acidic groups under 
Fig. 7 Relative changes in fractions of surface groups of medium (left) and weak (right) acidities for the studied roots grown at various water potentials $\psi$ in osmotic stress conditions induced by mannitol. On $y$-axis the ratio of fraction of a given groups of the roots grown at osmotic stress to the fraction of these groups in the control roots is given. The control roots (points at $C=0$ ) were grown without mannitol addition at $\psi=0$. Average values for each treatment are depicted. Error bars $\pm \mathrm{SD}$
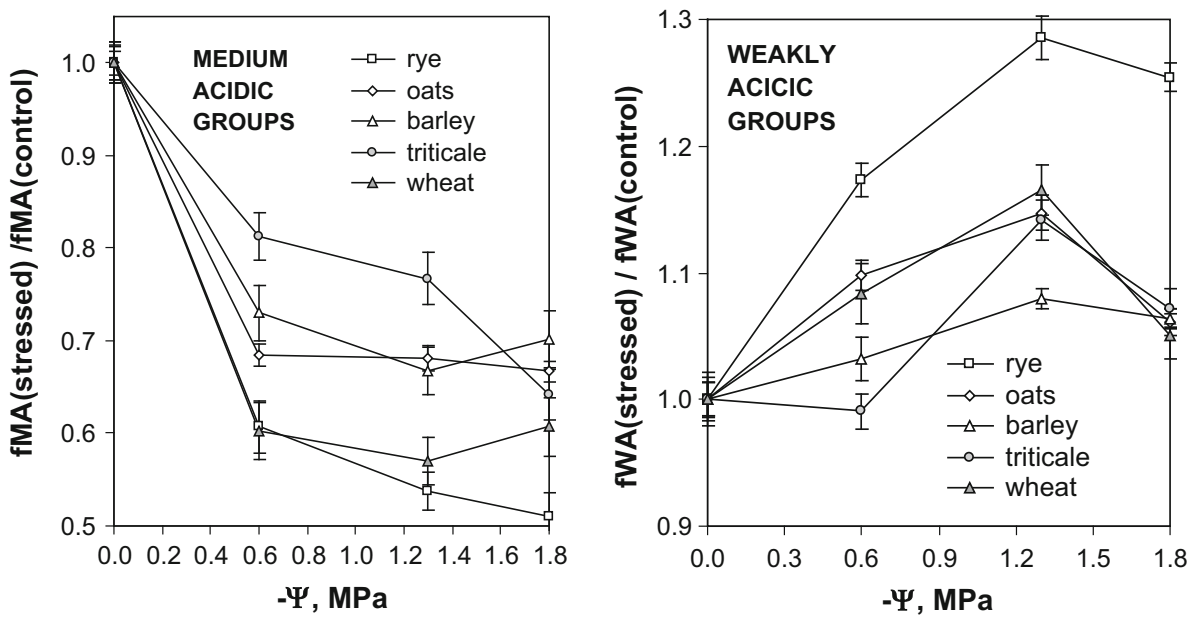

stress. These changes are balanced by increase in the amount of weakly acidic groups (see Fig. 7 and compare the behavior of peaks representing these groups in Fig. 5). Changes in amounts of different surface acidic groups may be caused by damage of the cell walls, outflow of the charged components from the cell interior, decrease in the amount of (charged) root hairs, partial root necrosis or growing of new roots. Most of these changes should be associated with an alteration of the chemical composition of the root tissue by stress. In this paper we did not study what changes in root tissue chemistry are responsible for the variable charge changes under stresses and this will be a subject of our further studies.

Lukowska and Jozefaciuk (2013) found that the intensities of the changes in roots CEC and $\mathrm{p} K_{\text {app }}$ apparently reflected the tolerance of barley varieties against drought. Basing on the obtained results this is hardly possible to distinguish drought tolerant and drought sensitive cereals.

\section{Conclusion}

Drastic changes in variable charge parameters of the roots under osmotic stresses may reflect the behavior of plants under drought because evaporation of soil water increases soil solution concentration and water availability for plants. As far as the CEC is primarily responsible for plant nutrient uptake, its decrease may cause severe nutrition hunger during soil drought or saline periods.

Author contribution statement M.L. performed the experimental works and G.J. prepared the English text and data interpretation. The idea, concept, calculations and all other contributions came from both authors.

Acknowledgments This work was supported by the European Regional Development Fund through the Innovative Economy
Program for Poland 2007-2013, Project WND-POIG.01.03.01-00101/08 POLAPGEN-BD "Biotechnological tools for breeding cereals with increased resistance to drought". The project is realized by POLAPGEN Consortium coordinated by Institute of Plant Genetics, Polish Academy of Sciences in Poznan. Further information about the project can be found at http://www.polapgen.pl.

Open Access This article is distributed under the terms of the Creative Commons Attribution 4.0 International License (http://creative commons.org/licenses/by/4.0/), which permits unrestricted use, distribution, and reproduction in any medium, provided you give appropriate credit to the original author(s) and the source, provide a link to the Creative Commons license, and indicate if changes were made.

\section{References}

Bian S, Jiang Y (2009) Reactive oxygen species, antioxidant enzyme activities and gene expression patterns in leaves and roots of Kentucky bluegrass in response to drought stress and recovery. Sci Hortic 120:264-270

Blum A (1996) Crop responses to drought and the interpretation of adaptation. Plant Growth Regul 20:135-148. doi:10.1007/ BF00024010

De Micco V, Aronne G (2012) Morpho-anatomical traits for plant adaptation to drought. In: Aroca R (ed) Plant responses to drought stress. Springer, Berlin, pp 37-61. doi:10.1007/978-3642-32653-0_2

Heintze SG (1964) Studies on cation exchange capacities of roots. Plant Soil 4:365-383

Jozefaciuk G, Szatanik-Kloc A (2004) Decrease in variable charge and acidity of root surface under Al treatment are correlated with Al tolerance of cereal plants. Plant Soil 260:137-145. doi:10. 1023/BPLSO.0000030175.23904.5a

Jozefaciuk G, Szatanik-Kloc A, Lukowska M, Szerement J (2014) Pitfalls and uncertainties of using potentiometric titration for estimation of plant roots surface charge and acid-base properties. Am J Plant Sci 5:1862-1876. doi:10.4236/ajps.2014.513200

Lukowska M, Jozefaciuk G (2013) Unknown mechanism of plants response to drought: low soil moisture and osmotic stresses induce severe decrease in CEC and increase in acidity of barley roots. J Agric Sci 5:204-213. doi:10.5539/jas.v5n10p204

Meychik NR, Yermakov IP (2001) Ion exchange properties of plant root cell walls. Plant Soil 234:181-193. doi:10.1023/A: 1017936318435 
Moayedi AA, Boyce AN, Barakbah SS (2009) Study on osmotic stress tolerance in promising durum wheat genotypes using drought stress indices. Res J Agric Biol Sci 5:603-607

Nederlof MM, De Wit JC, Riemsdijk WH, Koopal LK (1993) Determination of proton affinity distributions for humic substances. Environ Sci Technol 27:846-856. doi:10.1021/ es00042a006

Nezhadahmadi A, Prodhan ZH, Golam F (2013) Drought tolerance in wheat. Sci World J Article ID 610721. doi:10.1155/2013/610721

Nosalewicz A, Lipiec J (2014) The effect of compacted soil layers on vertical root distribution and water uptake by wheat. Plant Soil 375:229-240. doi:10.1007/s11104-013-1961-0

Oh MW, Komatsu S (2015) Characterization of proteins in soybean roots under flooding and drought stresses. J Proteomics 114:161-181

Radhouane L (2007) Response of Tunisian autochthonous pearl millet (Pennisetum glaucum (L.) R. Br.) to drought stress induced by polyethylene glycol (PEG) 6000. Afr J Biotechnol 6(9):1102-1105
Shan L, Yang C, Li Y, Duan Y, Geng D, Li Z, Zhang R, Duan G, Zhigunov AV (2015) Effects of drought stress on root physiological traits and root biomass allocation of Reaumuria soongorica. Acta Ecol Sin 35:155-159

Subbarao GV, Johansen C, Slinkard AE, Rao RCN, Saxena NP, Chauhan YS (1995) Strategies and scope for improving drought resistance in grain legumes. Crit Rev Plant Sci 14:469-523. doi:10.1080/07352689509701933

Szatanik-Kloc A (2010) Changes in surface properties of monocotyledonous and dicotyledonous plants determined by aluminum and copper toxicity. Acta Agrophys 176:1-183 (in Polish)

Williams DE, Coleman NT (1950) Cation exchange properties of plant root surfaces. Plant Soil 2:243-256. doi:10.1007/ BF01852352

Zlatev Z, Lidon FJC (2012) An overview on drought induced changes in plant growth water relations and photosynthesis. Emir J Food Agric 24:57-72 